XVI CONGRESO LATINOAMERICANO DE PATOLOGÍA DE LA CONSTRUCCÍN
XVIII DE CONTROL DE CALIDAD EN LA CONSTRUCCIÓN

\title{
Análise estática da superestrutura da ponte do Peixe Gordo, Tabuleiro do Norte, Ceará.
}

\author{
J. Beserra Filho ${ }^{1 *}$, E. Mesquita ${ }^{2}$ \\ 1 LAREB, Engenharia Civil, UFC, Campus Russas, Russas, CE. \\ 2 LAREB, Engenharia Civil, UFC, Campus Russas, Russas, CE. \\ *Autor correspondente: joao_moradanova@hotmail.com
}

\section{RESUMO}

Este trabalho se dedica em fornecer um aparato que facilite a compreensão sobre de que maneira se comporta, a superestrutura da Ponte do Peixe Gordo, estrutura sobre o rio Jaguaribe, que está localizada na cidade de Tabuleiro do Norte-CE. A ponte foi alvo de ataques, provenientes dos atentados criminosos no Ceará em 2019, os quais não ocasionaram danos relevantes a estrutura, gerando apenas danos superficiais. Não obstante, são apresentadas as análises estáticas, que forneceram dados que mostram a caracterização do comportamento da ponte. Conclui-se que os resultados obtidos permitiram identificar e analisar as concentrações de tensões e deformações, assim contribuindo para a compreensão sobre o comportamento estrutural, auxiliando em possíveis intervenções.

Palavras-chave: ponte; comportamento estrutural; análise estática.

\section{Static analysis of the superstructure of Peixe Gordo Bridge, Tabuleiro do Norte, Ceará.}

\author{
ABSTRACT
}


This work is dedicated to supply an apparatus that facilitates the understanding of how it behaves the superstructure of the Ponte do Peixe Gordo, a structure over the Jaguaribe River, which is located in the city of Tabuleiro do Norte-CE. The bridge was the target of attacks, originating from the criminal attacks in Ceará in 2019, which did not cause significant damage to the structure, generating only superficial damage to the structure. Nevertheless, static analyzes are presented, which provided data that show the characterization of the bridge's behavior. It is concluded that the results obtained allowed to identify and analyze the concentrations of stresses and deformations, thus contributing to the understanding of the structural behavior, assisting in possible interventions. Keywords: bridge; structural behavior; static analysis.

\section{Análisis estático de la superestructura del Puente del Peixe Gordo, Tabuleiro do Norte, Ceará.}

\section{RESUMEN}

Este trabajo está dedicado a proporcionar un aparato que facilite la comprensión de cómo se comporta, la superestructura del Ponte do Peixe Gordo, una estructura sobre el río Jaguaribe, que se encuentra en la ciudad de Tabuleiro do Norte-CE. El puente fue blanco de ataques, originados por los ataques criminales en Ceará en 2019, que no causaron daños significativos a la estructura, generando solo daños superficiales. No obstante, se presentan análisis estáticos, que proporcionaron datos que muestran la caracterización del comportamiento del puente. Se concluye que los resultados obtenidos permitieron identificar y analizar las concentraciones de tensiones y deformaciones, contribuyendo así a la comprensión del comportamiento estructural, asistiendo en posibles intervenciones.

Palabras llave: puente; comportamiento estructural; análisis estático.

\section{INTRODUÇÃO}


Pontes são obras de arte que tem a finalidade de interligar regiões, fazendo com que ocorra uma troca entre as regiões, nos aspectos econômico, cultural e intelectual, pois facilita o transporte das mais diversificadas mercadorias, pessoas e possibilita a comunicação. As pontes podem ocorrer para permitir a transposição de obstáculos, que podem ser rios, braços de mar, vales, e outras vias; e para que se tenha a continuidade de uma via, levando ao desenvolvimento da região.

Para Marchetti (2008), a estrutura capaz de transpor um obstáculo, sendo ele um rio, é denominado ponte, já quando o obstáculo transposto é um vale ou outra via, é denominado de viaduto. A estrutura de uma ponte é, na maioria das vezes, subdividida em superestrutura, mesoestrutura e infraestrutura. Estas estruturas são solicitadas por ações permanentes e ações variáveis. Neste aspecto, o peso próprio da estrutura principal e seus elementos secundários compõem, portanto, as cargas permanentes.

Ao se analisar uma estrutura é necessário levar em conta todas as ações e solicitações que possam interferir na sua segurança estrutural. Assim, a análise estrutural tem por propósito associar os sistemas físicos com ações externas atuantes, utilizando, para tal, modelos calibrados e suas propriedades, de modo que se possa caracterizar o comportamento global da estrutura analisada.

Nesse contexto, tem-se a Ponte do Peixe Gordo, esta que foi alvo de ataques criminosos, os quais ocasionaram apenas danos superficiais na estrutura, onde a camada de cobrimento de concreto foi destacada e fissurada. Com isso, faz-se viável e necessário a caracterização estrutural com o intuito de se verificar a segurança estrutural da ponte, e que, posteriormente, possam embasar o órgão responsável pela ponte, em possíveis reparos e intervenções em sua estrutura.

Para isso, a elaboração das atividades se baseia no comportamento estrutural da superestrutura da ponte do Peixe Gordo, através da análise estática. Logo, buscou-se a um modelo no qual foi aplicado uma resolução numérica baseada em um sistema de equações diferenciais, denominado Método dos Elementos Finitos. Assim, foi possível a obtenção dos deslocamentos direcionais e total, e as tensões de tração e compressão ocorrentes nos elementos da estrutura.

\section{ESTUDO DE CASO}

\subsection{A Ponte do Peixe Gordo}

A ponte estudada neste trabalho é a Ponte do Peixe Gordo, localizada na rodovia BR-116, mais precisamente no Km 204, no distrito de Peixe Gordo, no município de Tabuleiro do Norte, Ceará. A ponte tem como obstáculo transposto, o rio Jaguaribe, sua extensão total é de 412 metros, sua superestrutura tem extensão de 390 metros, subdivididos em 11 vãos, nove destes com o comprimento de 37 metros e suas extremidades com 28,50 metros. A construção da ponte é datada de 1948, passando no decorrer dos anos por algumas intervenções para a melhoria da sua utilização, visto o crescimento do tráfego que motivou o alargamento da ponte em 2001. 


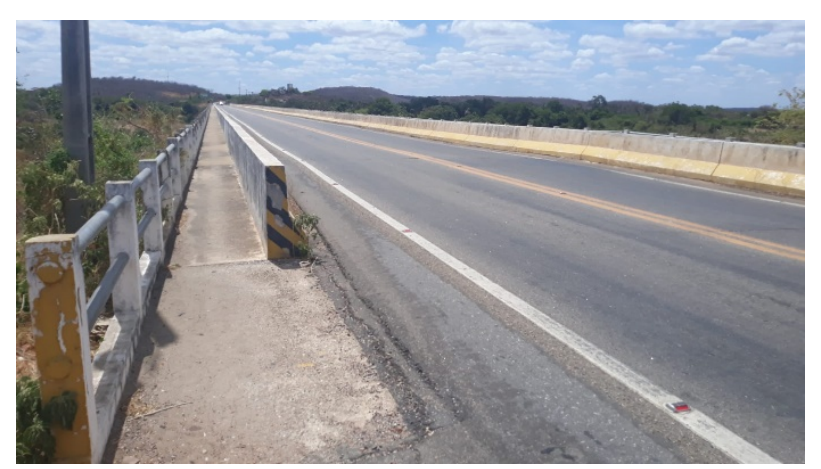

Figura 1. Ponte do Peixe Gordo.

Com o intuito de se verificar a segurança estrutural da ponte, alguns estudos técnicos foram realizados, dentre os quais, análises computacionais, das quais deriva este trabalho.

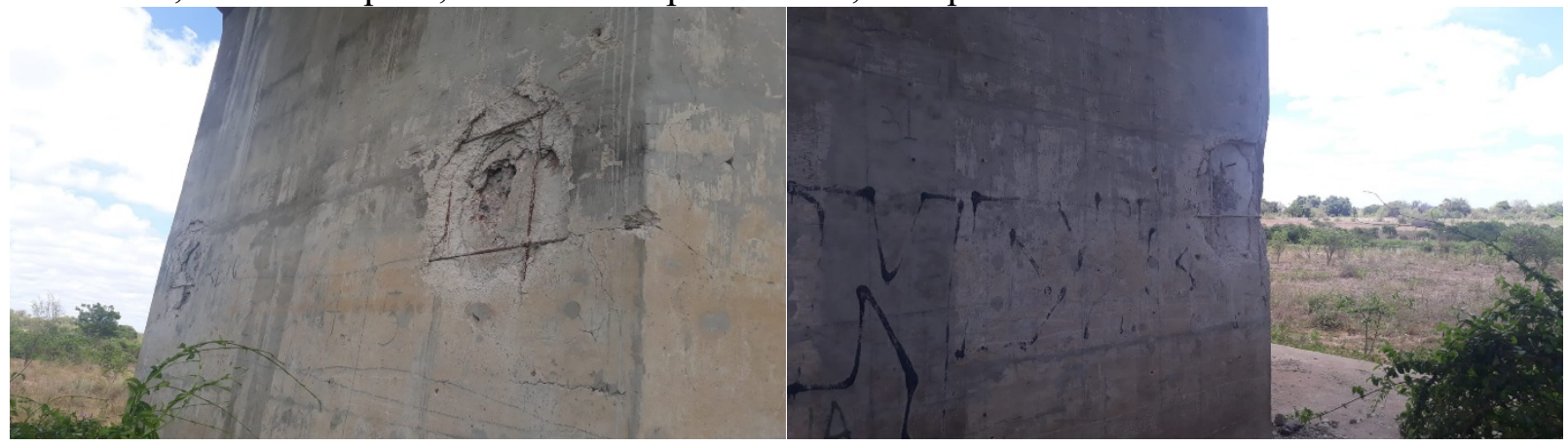

Figura 2. Danos causados por ataques criminosos em 2019.

\subsection{Superestrutura}

A superestrutura é composta pelos elementos estruturais a seguir, são eles, as vigas principais (com alargamento nas proximidades dos pilares), a laje do tabuleiro (pista de rolamento, com acréscimo do revestimento e passarela de passeio), as guarda-rodas e os guarda-corpo.

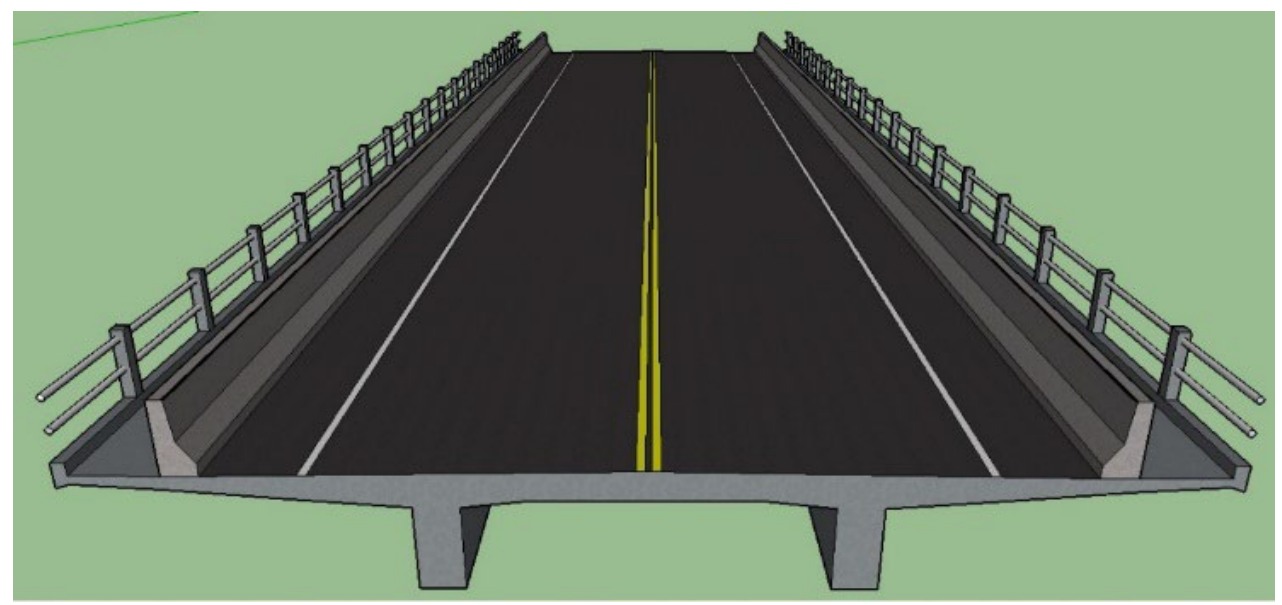

Figura 3. Superestrutura da ponte.

\subsection{Modelagem numérica da estrutura}


Para a modelagem numérica, buscou-se a elaboração de um modelo 3D que representasse a superestrutura da ponte. Para isso foram utilizadas as informações de projetos (DNIT), onde possibilitou a construção do modelo que representasse a estrutura da ponte o mais fidedigno possível às suas características. Em seguida, se obteve a malha de elementos finitos. Com isso, obteve-se uma malha composta por 192.784 elementos e 394.252 nós. A Figura 3 mostra um vão do modelo 3D obtido.
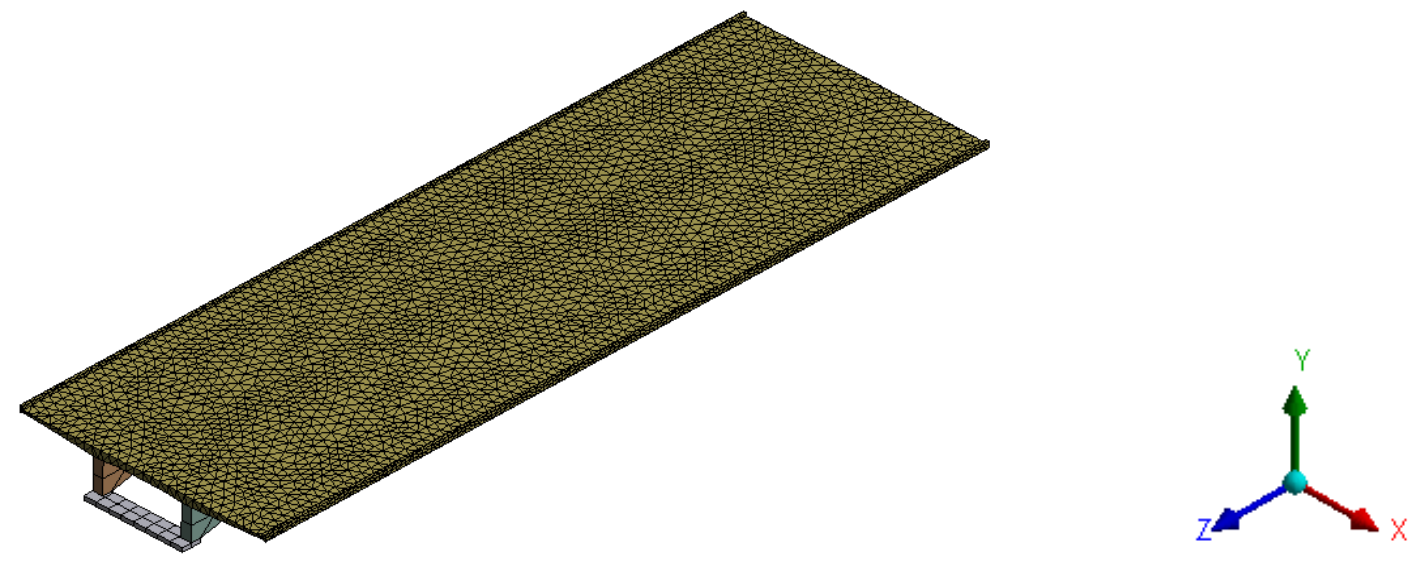

Figura 4. Modelo 3D em malha de elementos finitos.

\subsection{Carregamentos e propriedades mecânicas}

Os carregamentos aplicados nesta análise foram as ações permanentes das pontes, de acordo com a NBR 8681 (2003), são as cargas constantes, ou seja, peso próprio dos elementos da superestrutura. Os elementos da superestrutura que estão no modelo 3D são as vigas e a laje, para os demais elementos adotaram-se forças para substituir o peso próprio, são eles: guarda-rodas, guarda-corpo e revestimento, assim os carregamentos permanentes estão aplicados na estrutura, onde facilitou a construção da malha do modelo.

Para o cálculo dos carregamentos, o material utilizado em todo o modelo foi o de características que se semelham ao concreto armado. Adotando assim, os seguintes parâmetros, encontrados em Pinheiro (2007), para as propriedades mecânicas do material: considerou-se o módulo de elasticidade $(\mathrm{E})$ de $30 \mathrm{GPa}$, o peso específico $(\mathrm{w})$ de $25 \mathrm{kN} / \mathrm{m}$, a resistência à compressão $\left(\mathrm{f}_{\mathrm{c}}\right)$ de $25 \mathrm{MPa}$, a resistência a tração $\left(\mathrm{f}_{\mathrm{t}}\right)$ de $3 \mathrm{MPa}$ e o coeficiente de Poisson $(v)$ de 0,20 . As propriedades estão dispostas na Tabela 1.

Tabela 1. Propriedades mecânicas adotadas no modelo numérico para análise estática.

\begin{tabular}{|c|c|c|}
\hline Propriedade Mecânica & Magnitude & Unidade \\
\hline $\mathrm{E}$ & 30,00 & $\mathrm{GPa}$ \\
\hline $\mathrm{w}$ & 25,00 & $\mathrm{kN} / \mathrm{m}^{3}$ \\
\hline $\mathrm{f}_{\mathrm{c}}$ & 25,00 & $\mathrm{MPa}$ \\
\hline $\mathrm{f}_{\mathrm{t}}$ & 3,00 & $\mathrm{MPa}$ \\
\hline$v$ & 0,20 & adimensional \\
\hline
\end{tabular}

\section{RESULTADOS}

\subsection{Deslocamentos direcionais}


O início da análise da superestrutura se deu após adicionadas as características dos materiais e as cargas, pela qual foram obtidos os deslocamento direcionais nos eixos $\mathrm{X}, \mathrm{Y}$ e $\mathrm{Z}$. O eixo $\mathrm{X}$ corresponde ao sentido transversal horizontal da ponte, o eixo $\mathrm{Y}$ no sentido vertical e o eixo $\mathrm{Z}$ no sentido longitudinal horizontal.

Os deslocamentos direcionais no eixo X estão representados na Figura 5, onde verifica-se que o deslocamento, no sentido positivo do eixo, tem amplitude de aproximadamente 1,03 mm, localizada na viga do vão 9. Já na direção negativa do eixo, o deslocamento tem amplitude de, aproximadamente, $0,88 \mathrm{~mm}$, localizada na viga do vão 11 .
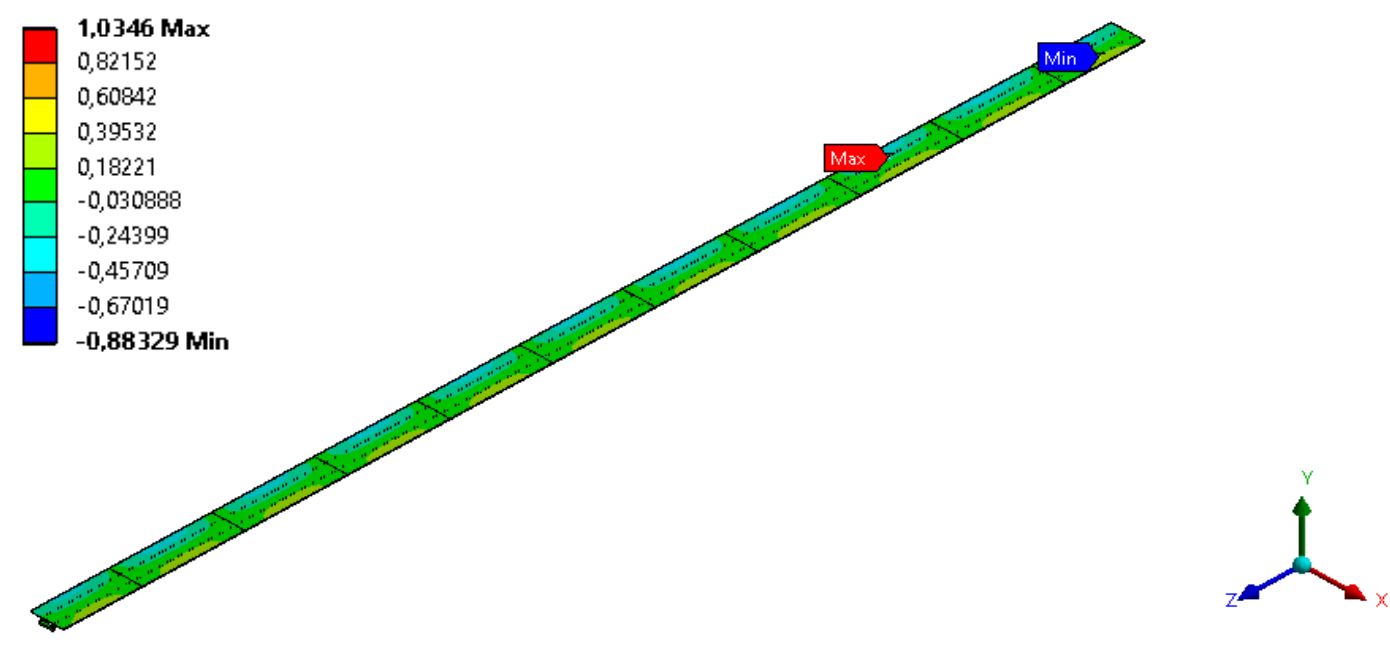

Figura 5. Deslocamentos direcionais no eixo X com unidade em milímetros.

Os deslocamentos direcionais no eixo $\mathrm{Z}$ estão representados na Figura 6, onde verifica-se que o deslocamento, no sentido positivo do eixo, tem amplitude de aproximadamente $3,31 \mathrm{~mm}$, localizada na viga do vão 10. Já na direção negativa do eixo, o deslocamento tem amplitude de, aproximadamente, $3,31 \mathrm{~mm}$, localizada na viga do vão 2 .
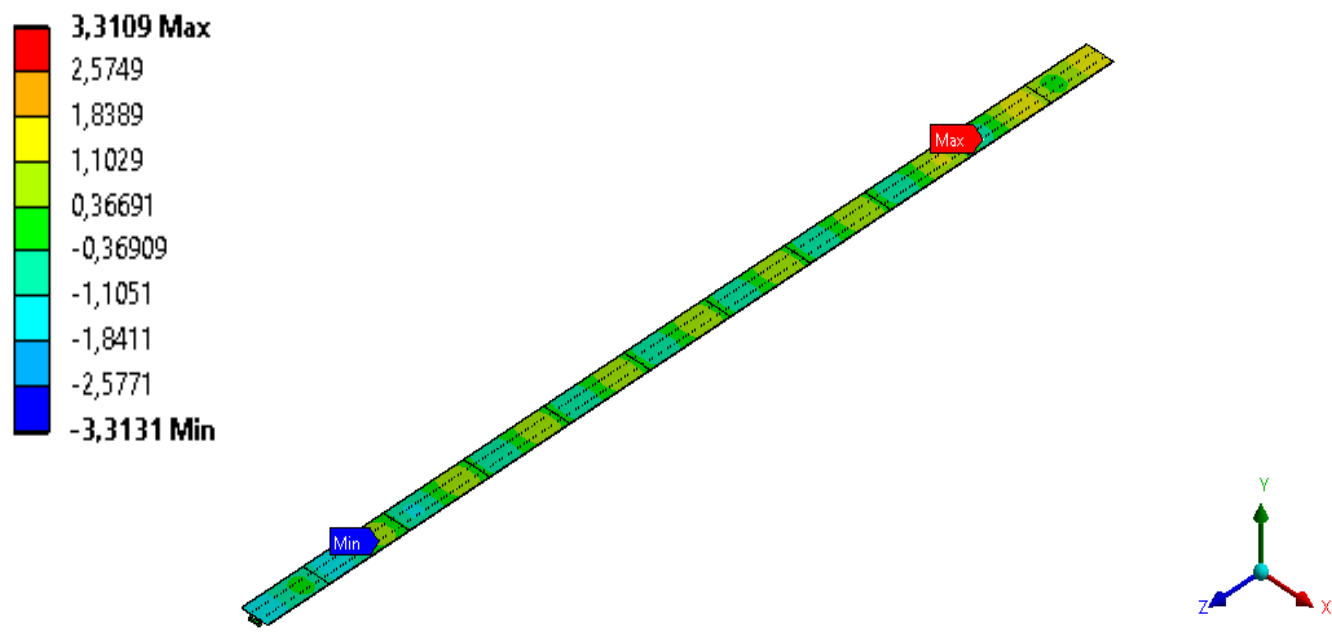

Figura 6. Deslocamentos direcionais no eixo Z com unidade em milímetros. 
Para o eixo Y apresenta os deslocamentos, para o eixo positivo, de menor intensidade, cerca de $0,66 \mathrm{~mm}$, entretanto o eixo negativo contém maior amplitude, $40,68 \mathrm{~mm}$. A menor intensidade está localizada na extremidade livre da laje do vão 11. A maior intensidade está localizada na borda lateral da laje do vão 10 .
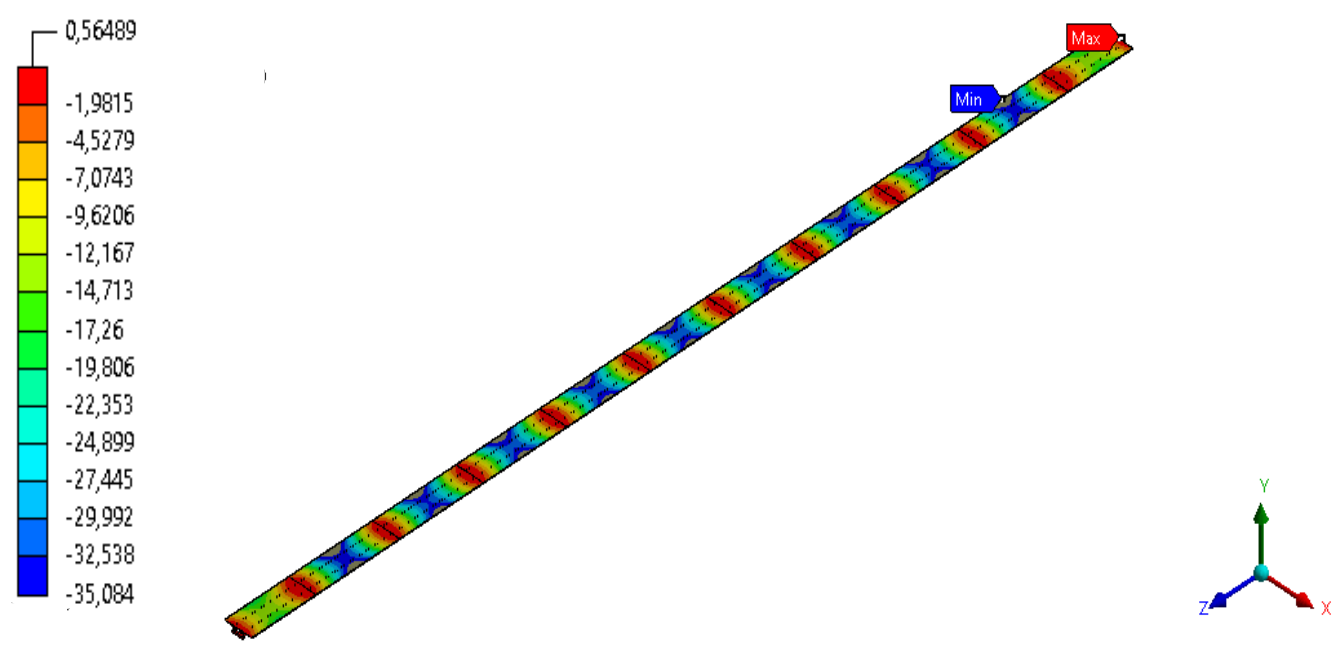

Figura 7. Deslocamentos direcionais no eixo Y com unidade em milímetros.

\subsection{Deslocamento total}

Com os deslocamentos direcionais, foram obtidos os resultados referentes ao deslocamento total apresentado pela estrutura da ponte do Peixe Gordo, representado na Figura 8. Nota-se a simetria nos deslocamentos na ponte, onde o deslocamento máximo, foram localizadas nas bordas laterais da laje dos vãos 02 e 10, que é igual a 40,68 mm.
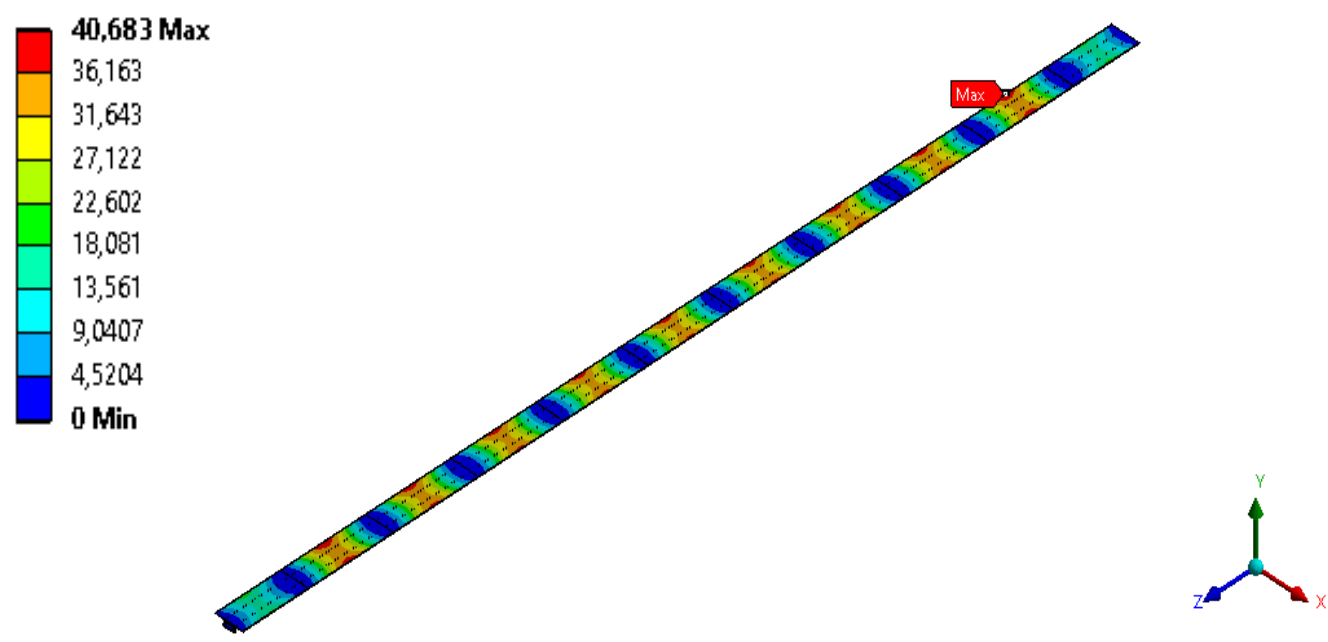

Figura 8. Deslocamento total com unidade em milímetros.

\subsection{Tensões principais}

A Figura 9 apresenta as tensões principais de tração atuantes na superestrutura da ponte. Os maiores valores de tração encontrados, estão localizados no meio das extremidades inferiores das vigas 
(Figura 9.b), onde a maior intensidade encontrada foi no meio do vão 6 (vão central), cerca de 13,21 MPa. Vale salientar que as tensões ultrapassam a resistência característica a tração adotada, de 3,00 MPa.

a) $\begin{array}{ll}\mathbf{1 3 , 2 0 7} \text { Max } \\ 11,418 \\ 9,6292 \\ 7,8403 \\ 6,0515 \\ 4,2627 \\ 2,4738 \\ 0,68498 \\ -1,1039 \\ -2,8927 \text { Min }\end{array}$
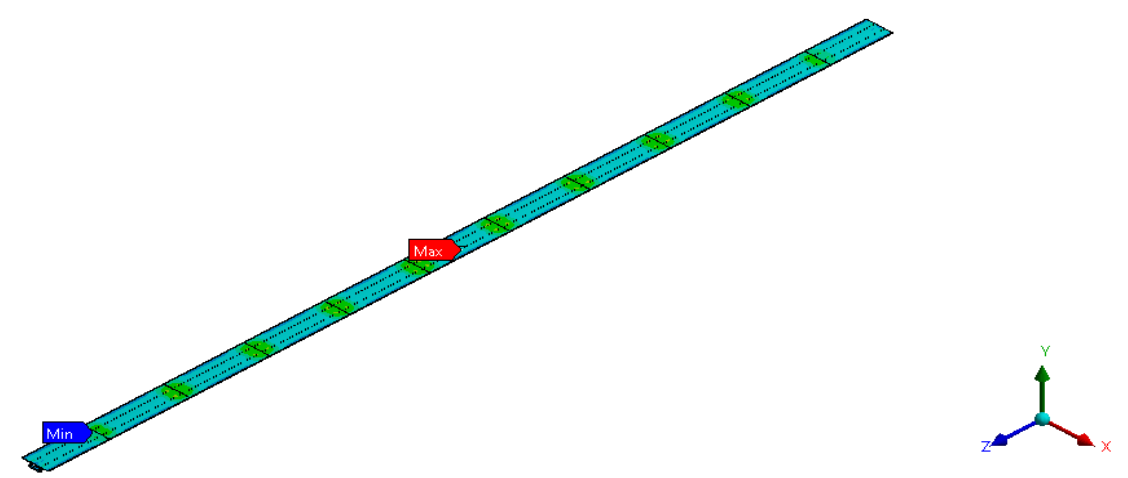

b)
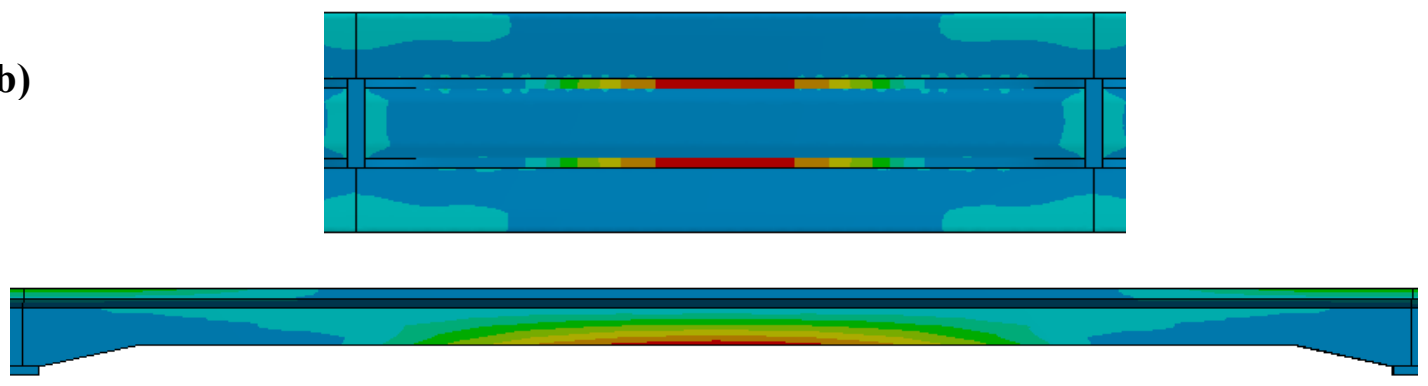

Figura 9. Tensões principais de tração no modelo, unidade em Pascal. (a) Vista em perspectiva, (b) Vistas da viga principal, ponto de maior intensidade.

Já, a Figura 10, apresenta as tensões principais de compressão, os maiores valores estão localizados nas extremidades inferiores dos alargamento das vigas principais, próximo aos apoios dos pilares (Figura 10.b), onde a maior intensidade encontrada, foi de 25,28 $\mathrm{MPa}$. 

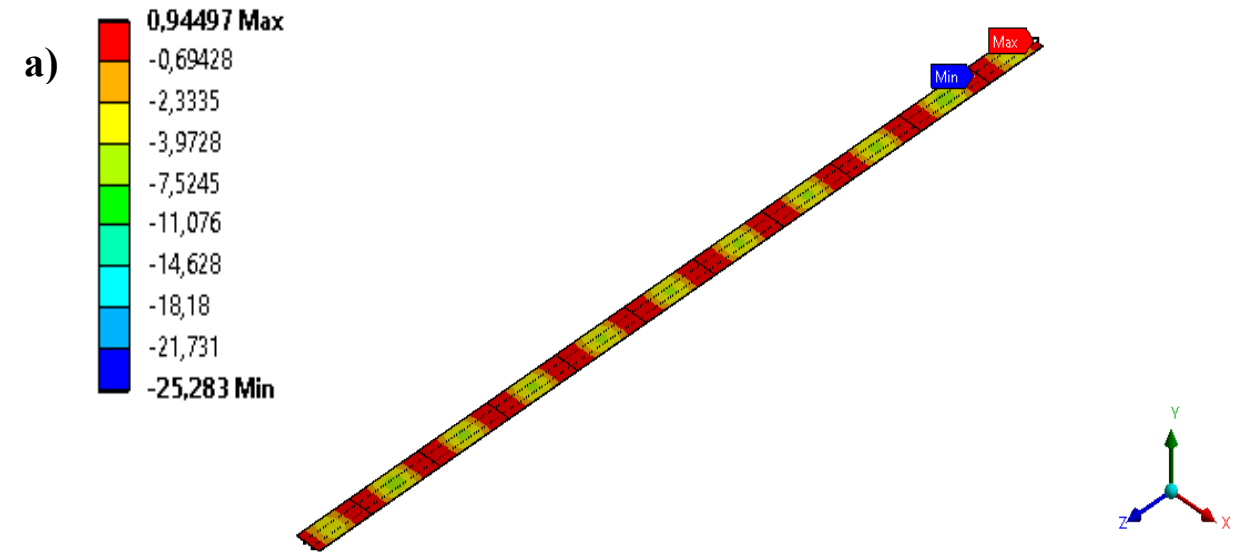

b)
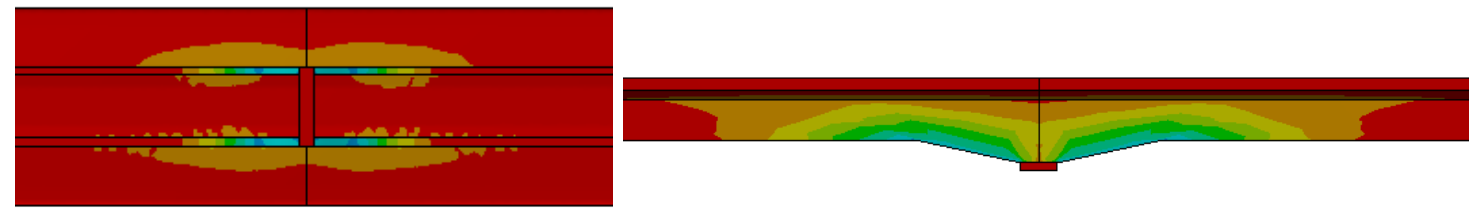

Figura 10. Tensões Principais de compressão no modelo, unidade em Pascal. (a) Vista em perspectiva, (b) Vistas da viga principal, ponto de maior intensidade.

\section{CONCLUSÃO}

A ponte do Peixe Gordo, com extensão total de 412 metros, é uma obra significante localizada na BR 116. Logo, por conta de ataques criminosos, provenientes dos atentados criminosos no Ceará em 2019, a fim de interromper esta travessia, com isso a realização da análise estrutural, foi necessário para proporcionar informações a respeito do comportamento da estrutura.

A utilização da análise estrutural via método dos elementos finitos é um aparato importante para a segurança estrutural, pois por meio da modelagem, foram apresentadas as regiões que sofrem maiores solicitações e que porventura possam apresentar danos a estrutura.

No que concerne aos deslocamentos direcionais, obteve-se os resultados que não demonstraram serem indicadores de um eventual sinistro estrutural, apresentaram deslocamentos iguais a 1,03 milímetros para o eixo X, 3,31 milímetros para o eixo Z, e 40,68 milímetros para o eixo Y, maior amplitude obtida. Logo, o deslocamento total obtido na análise, foi de 40,61 milímetros localizado na borda lateral da laje do vão 10. Quanto as tensões principais, os esforços de tração presentes ultrapassam a resistência característica adotada, com máxima de 13,21 $\mathrm{MPa}$, os esforços de compreensão apresentaram uma amplitude máxima de $25,28 \mathrm{MPa}$, valor maior que a resistência adotada no modelo, com isso tem-se a possibilidade do surgimento de danos.

Os modelos numéricos utilizados asseguram dados viáveis, que permitem compreender o comportamento da estrutura e avaliar o nível de tensões atuantes, bem como localizar essas tensões no plano geométrico, com isso expandindo o conhecimento acerca do comportamento e vulnerabilidade dessas estruturas, para auxiliar na manutenção da segurança e preservação. 


\section{REFERÊNCIAS BIBLIOGRÁFICAS}

Associação Brasileira De Normas Técnicas. (2003). NBR 8681: ações e segurança nas estruturas - procedimentos. Rio de Janeiro.

Marchetti, Osvaldemar. (2008). Pontes de concreto armado. Blucher, São Paulo.

Pinheiro, L. M. (2007). Fundamentos do concreto e projeto de edifícios. Universidade de São Paulo, São Carlos. 